\title{
A boa Índole M oral: como o governo se constitui em uma comunidade de alemães da Encosta da Serra, RS ${ }^{1}$
}

Everton de Oliveira ${ }^{2}$

\section{Resumo}

Neste artigo, analiso como a moral implicada na relação entre trabalho/dor/sofrimento é capaz de produzir governo em uma colônia alemã. Para tanto, parto de meu trabalho de campo realizado em um município que aqui chamo de São Martinho, situado na região da Encosta da Serra, RS. A intensa dedicação de seus moradores ao trabalho, associada aos efeitos que lhe são creditados - dor e sofrimento -, eram em si o princípio ativo da socialidade martinense, além de lhe servirem de apreciação moral. A gestão pública integrava igualmente esse arranjo ao ser comumente avaliada enquanto fruto da boa índole moral de seus gestores. 0 limite categórico dessa socialidade era a $\mathrm{Co}$ munidade de alemães, que abarcava a complexidade do governo em São Martinho de forma mais precisa do que a categoria analítica de Estado.

Palavras-chave: Encosta da Serra; governo; sofrimento; moral

\footnotetext{
${ }^{1}$ Uma versão anterior deste trabalho foi apresentada sob o título "A boa índole moral: o que se espera de um administrador público em uma colônia alemã da Encosta da Serra, RS" na 29a Reunião Brasileira de Antropologia, realizada entre os dias 03 e 06 de agosto de 2014, Natal/RN. Nela, ainda não constavam as problematizações da relação entre trabalho/dor/sofrimento para o funcionamento do governo em São Martinho.

${ }^{2}$ Doutorando do Programa de Pós-Graduação em Ciências Sociais do Instituto de Filosofia e Ciências Humanas da Universidade Estadual de Campinas (IFCH/Unicamp). Bolsista da Fundação de Amparo à Pesquisa do Estado de São Paulo (Fapesp). Membro do Laboratório de Antropologia da Religião (LAR/IFCH/Unicamp). E-mail: evtdeoliveira@ gmail.com
} 


\section{Good M oral Character: how the government is constituted in a german community of encosta da serra, southern Brazil}

\section{Abstract}

In this paper, I analyze how the moral implied in the relation between work/pain/suffering is able to produce government in a German colony. Therefore, I make use of my fieldwork conducted in a municipality here called São Martinho, situated in the region of Encosta da Serra, southern Brazil. The intense dedication of its inhabitants to work, combined with its effects - pain and suffering - were themselves the active ingredient in martinense sociality, as well as serve as moral appreciation. Public management also was part of this arrangement to be commonly assessed as a result of good moral character of their managers. The categorical limit of this sociality was the comunidade de alemães, which embraced the complexity of government in São Martinho more accurately than the analytical category of state.

Keywords: Encosta da Serra; government; suffering; moral

Cada família construía sua própria casa e, depois, ajudava a construir a casa das outras famílias. Como não tinham professor, escolheram a pessoa de melhor índole moral para ensinar língua e religião para as crianças. Como também ainda não tinham padre, escolheram uma pessoa de tão boa índole moral para cuidar da religião (Júlio Hoff, historiador e secretário de Planejamento e Assistência Social de São Martinho).

A fala com que abro este artigo foi, na verdade, um pequeno discurso de Júlio Hoff ${ }^{3}$, no momento em que deixava a Secretaria

\footnotetext{
${ }^{3}$ Todos os nomes - e sobrenomes - de pessoas, lugares, cidades ou instituições, assim como as datas oficiais, diretamente relacionadas ao artigo, foram alterados. A alteração procura evitar qualquer tom denunciativo ou jornalístico a este texto, assim como busca preservar as identidades de meus colaboradores de pesquisa, sem os quais este trabalho não poderia ser escrito.
} 
de Saúde de São Martinho para assumir a Secretaria de Planejamento e Assistência Social do mesmo município. 0 momento em que este ocorreu foi o da transição da equipe do governo municipal, decorrente dos resultados das eleições municipais de 2012. Apesar da mesma coligação ${ }^{4}$ que havia ocupado a administração pública há quatro anos ter ganhado novamente o pleito eleitoral, as mudanças na equipe eram esperadas, especialmente no que tocava o caso de Júlio Hoff, figura polêmica na política municipal.

Este artigo partirá, então, deste pequeno intervalo etnográfico entre os últimos dias de 2012 e os primeiros dias de 2013, isto é, o período de transição do governo municipal. Esse período trouxe à tona uma série de novas composições de grupo impulsionadas pelas desavenças que não mais permaneciam no silêncio. Essas composições eram de toda ordem, de família ${ }^{5}$, de grupos políticos, de casa e, evidente, de governo. Partindo de minha etnografia sobre esse período, o objetivo deste trabalho é analisar de que modo a produção de governo se relaciona à produção correlata de grupos e pessoas em São Martinho, vinculadas à valoração moral do trabalho por parte de seus moradores. Minha aposta é que nesse município o principal efeito creditado ao trabalho, o de causar dor e sofrimento a quem a ele se dedica, é igualmente o princípio motor de suas relações sociais, capaz de formar e informar sobre grupos e pessoas, entre os quais se inclui o governo. Nesse sentido, para falar de administração pública no nível de uma etnografia da

\footnotetext{
${ }^{4}$ A Coligação Eleitoral é uma prerrogativa da disputa política garantida pelo Art. 10 da Lei das Eleições (Lei n. 9.504/1997), assim como pelo Art. 17, § 1ํ, da Constituição Federal, alterado pela Emenda Constitucional (EC) n. 52 de 2006 (TSE, 2012). A Coligação permite a partidos políticos unirem-se para a disputa eleitoral majoritária e proporcional, ou para ambas, sendo, neste caso, permitido que se forme mais de uma coligação para as eleições proporcionais dentre aqueles partidos que formam uma coligação majoritária. A EC n. 52 (Brasil, 2005) garante justamente a autonomia dos partidos políticos em definirem os critérios de escolha e o regime de suas coligações, sem obrigatoriedade de vinculação entre as candidaturas em âmbito nacional, estadual, distrital ou municipal. ${ }^{5}$ As palavras em itálico são, em sua maioria, categorias sociais que circulavam em São Martinho. Grande parte dessas categorias estrutura a análise etnográfica e, por isto, serão desenvolvidas e problematizadas no próprio corpo do texto ou em notas de rodapé.
} 
política, passaremos inevitavelmente por questões relativas à moral e à ética de moradoras e moradores, para os quais a burocracia é coextensiva às relações sociais que fundamentam o cotidiano e as narrativas de comunidade.

São Martinho possui uma história similar a dos municípios que o cercam na região da Encosta da Serra, Rio Grande do Sul. Ocupado em meados do século XIX por imigrantes alemães, formou-se enquanto uma comunidade de parentes, que construíram suas casas principalmente no vale que se formava na região central do município, mas também em seus platôs - um deles chamado de Mirante. Os que participam dessa comunidade chamam-se alemães. Os alemães não estão vinculados apenas a São Martinho: espalham-se pela Encosta da Serra, na qual o maior município é Germana, com cerca de 27.000 habitantes, vizinho de São Martinho, que possui aproximadamente 6.000 habitantes (IBGE, 2010). Diferentemente dos municípios que se encontram na Serra Gaúcha, a Encosta da Serra não participa do mesmo apelo turístico, valendo-se de suas indústrias calçadistas ${ }^{6}$ e de sua agropecuária ${ }^{7}$ como principais atividades econômicas ${ }^{8}$.

\footnotetext{
${ }^{6}$ Pelos relatos de moradores, as indústrias calçadistas - as fábricas - passaram a se instalar há pelo menos 30 anos em São Martinho, sendo a maior delas situada no Centro, bem próximo à Igreja Matriz. Segundo o Cadastro Geral de Empregados e Desempregados (CAGED) do Ministério do Trabalho e Emprego (MTE), em janeiro de 2012, a indústria calçadista empregava 1.282 pessoas em São Martinho (MTE, 2012), ou seja, 21,17\% de sua população total (IBGE, 2010).

${ }^{7}$ Os que se dedicam à agropecuária em São Martinho chamam-se, comumente, de colonos. Entre os alemães, aqueles que se reconheciam por colonos geralmente possuíam alguma roça, o que era a situação mais comum na cidade. Mesmo que não se buscasse vender os produtos da roça - os mais comuns eram a batata, o milho, a acácia (para lenha) e hortaliças, e a criação de galinhas, porcos e vacas - alguma plantação ou criação era sempre mantida no próprio terreno, ou em terreno vizinho, para consumo próprio ou para troca entre os vizinhos. Isso fazia com que a divisão entre espaço urbano e espaço rural fosse pouco eficaz no município.

${ }^{8} 0$ que de certa forma influencia positivamente para o fato de São Martinho estar entre os 10 municípios mais igualitários do Brasil, com um índice de Gini - variável entre 0 e 1 e utilizado para medir a desigualdade socioeconômica - de 0,30, segundo o Atlas do Desenvolvimento Humano no Brasil, produzido pelo Programa das Nações Unidas para o Desenvolvimento (PNUD) da Organização das Nações Unidas (ONU) (PNUD, 2013).
} 
O artigo percorrerá pelo período de transição de governo de São Martinho, buscando justamente descrever e analisar a série de composições presentes na disputa política municipal. Por se tratar de um contexto etnográfico singular, partirei da formação social e histórica de São Martinho, mais precisamente dos aspectos que Júlio Hoff trouxe à tona em seu discurso, de modo não apenas a introduzir o campo etnográfico, mas também oferecer os componentes históricos que eram constantemente operacionalizados por candidatos e moradores na disputa política de 2012. Logo em seguida, buscarei destacar seus pormenores políticos e sociais, a partir de uma breve análise de como se dava a disputa política em São Martinho, seus grupos políticos, que implicava algumas sobreposições de grupo e preceitos morais partilhados. 0 que levará à análise da comunidade de São Martinho, como o ideal moral que a disputa política não deixava de levar em conta, e suas implicações na formação de pessoas, casas e famílias na organização social dos alemães. Para terminar, tratarei da formação de governo, formado pelas mesmas relações sociais que permitiam a categorização da comunidade (o que me levará a tecer algumas notas sobre a validade da categoria "Estado" em uma análise etnográfica da política e da burocracia, encarada frente a frente com a composição de governo observada em São Martinho, buscando destacar os limites que tal categoria oferece à escrita etnográfica).

\section{$\mathrm{O}$ discurso de Júlio $\mathrm{H}$ off}

O pequeno discurso de Júlio Hoff era direcionado a funcionários e gestores envolvidos na administração da saúde pública de São Martinho, no dia 2 de janeiro de 2013. Eu também estava presente, na época fazia meu terceiro período de trabalho de campo referente à pesquisa de mestrado ${ }^{9}$ sobre a implementação da

\footnotetext{
${ }^{9}$ Pesquisa que deu origem à dissertação de mestrado "Promover a Saúde, Produzir Famílias: a implementação da Estratégia Saúde da Família na Encosta da Serra gaúcha”, defendida em 2013 no Programa de Pós-Graduação em Sociologia da Universidade Federal de São Carlos (UFSCar).
} 
Estratégia Saúde da Família no município. Júlio, então, deixava a Secretaria Municipal de Saúde para assumir a Secretaria Municipal de Planejamento e Assistência Social, recém-criada pela nova equipe de governo. As notícias sobre a política municipal, que corriam entre os moradores mais informados - e inflamados - sobre a disputa política, garantiam que tal mudança havia sido uma estratégia engenhosa do prefeito municipal reeleito, Paulo Ritter. Nessa versão, Paulo sabia da importância de ter Júlio como aliado político, mas sofria pressões de seu próprio grupo para tirá-lo da Secretaria de Saúde. Eis que surge, no momento da posse, uma nova Secretaria Municipal, com Júlio responsável por sua administração. De certo modo, essa era a versão aceita também por Júlio, e esta foi uma das pautas do encontro do dia 2 de janeiro.

Segundo Júlio, há quatro anos o prefeito fora lhe pedir insistentemente para que ele assumisse a Secretaria de Saúde. Júlio tinha o costume de enfatizar sua participação na história municipal, o que, de fato, não era infundado. Com pouco mais de 20 anos de idade, em 1972, assumiu a presidência do Hospital São José, no Centro de São Martinho. Pouco tempo depois iniciou seu magistério no Colégio Estadual Cônego Bruno Hamm, no qual lecionava história e chegou ao cargo de diretor, que deixou justamente quando assumiu a Secretaria Municipal de Saúde, em 2009. Antes disso, porém, participou da Comissão Emancipadora responsável por enviar o projeto de emancipação política de São Martinho - em relação à Germana - à Assembleia Legislativa do Rio Grande do Sul, aprovado em 1988, pelo então governador Pedro Simon - que se tornaria um importante aliado de Júlio. Participou também da formulação do 1ํo Plano Municipal de Saúde, em 1991, quando era secretário municipal de Educação. Quando retornou à gestão municipal, em 2009, ampliou as duas Equipes de Saúde da Família do município, além de canalizar o sistema de saúde municipal para as duas Unidades de Saúde da Família (USFs) - uma no bairro Mirante e uma no centro da cidade -, visto por ele como uma medicina comunitária. 
Não por menos, Júlio Hoff ressaltava sua importância na política municipal. Em seu discurso, disse que mesmo receoso em deixar a direção do Colégio Cônego, porque, após muitos anos de trabalho na instituição, havia construído uma família, aceitou o convite de assumir a Secretaria de Saúde. Neguei uma, neguei duas, mas na terceira vez, aceitei. Para tanto, precisou convencer sua família, esposa e filhos, de que essa era uma decisão acertada, apesar do receio de todos. E, como condição, pediu a Paulo Ritter para que tivesse total autonomia na gestão da Secretaria de Saúde, para que colocasse em prática aquilo que havia aprendido na formulação do 1ํo Plano Municipal de Saúde. Em sua fala, Júlio traçou toda sua trajetória de mais 35 anos de vida pública, [em que] construí três famílias: uma em casa, uma na direção do [colégio] Cônego, e uma na [Secretaria de] Saúde. Quando assumiu a Secretaria, Júlio queria construir um sistema de saúde que funcionasse e que atendesse a comunidade. Foi por isso que manteve o mesmo médico da USF do bairro Mirante, pois, apesar de não ser um médico comunitário (Médico de Família e Comunidade ${ }^{10}$ ), ele já conhecia e era muito atencioso com as famílias de sua área. Na mesma direção, achava imprescindível contratar um médico comunitário para cuidar da USF do Centro que, quando assumiu, ainda não tinha uma equipe formada.

No decorrer do discurso, Júlio ressaltou que o que faltava então a São Martinho era um senso de comunidade, como aquele que os primeiros colonos mantinham entre si. Naquele tempo havia o que para ele atualmente se perdera: companheirismo, senso de comunidade. Cada família construía sua própria casa e, depois, ajudava a construir a casa das outras famílias. Como não tinham professor, escolheram a pessoa de melhor índole moral para en-

\footnotetext{
${ }^{10}$ A Medicina de Família e Comunidade está instituída no Brasil desde 1976, sob a forma de Programa de Residência em Medicina de Família e Comunidade (RMFC) da Faculdade de Ciências Médicas/Uerj, e também sob a forma dos Programas de Residência em Medicina Geral Comunitária (RMGC), de Murialdo, Porto Alegre (Grupo Hospitalar Conceição) e Vitória de Santo Antão, que, em 2002, receberiam a mesma denominação do programa da Uerj (Rodrigues, 2007, p. 150).
} 
sinar língua e religião para as crianças. Como também ainda não tinham padre, escolheram uma pessoa de tão boa índole moral para cuidar da religião. A primeira capela construída foi a do Morro da Mata e, em 1905, lançaram a pedra fundamental para a construção da Igreja Matriz, no centro, que ficou pronta em 1931. Foi então enviado o primeiro pároco para São Martinho, o cônego Bruno Hamm. A comunidade decidiu, então, formar uma sociedade beneficente: a Sociedade Beneficente São José, a qual um dos fundadores era o cônego. A Sociedade lançou, então, o projeto de construção de um hospital comunitário - futuro Hospital São José - e, como em São Martinho não havia material de construção disponível para uma construção desse porte, foram buscar, em lombo de burro, tijolos e material necessários para a construção. Se fosse hoje, enfatizava Júlio, aquele hospital não seria construído. Quando em funcionamento, pela difícil manutenção de um hospital comunitário, o último médico contratado pelo hospital entrara com uma ação contra sua direção, exigindo o pagamento de honorários atrasados. Isso foi em 1972. 0 prefeito de Germana, então responsável pelo distrito de São Martinho, entregou sua carta de demissão ao padre e jogou a bucha para a Igreja - católica, de Germana. Organizou-se, então, novas eleições em Germana, com a ajuda da Igreja, quando se elegeu o prefeito Umberto Gruber, sendo seu sobrinho, Mauro Gruber ${ }^{11}$, designado para ser subprefeito de São Martinho. 0 novo prefeito de Germana, parte da comunidade de São Martinho, assim como alguns políticos interessados, se reuniram para procurar uma solução para a dívida do hospital, quando Umberto Gruber apontou para Júlio, então professor de um colégio do Morro da Mata, região montanhosa próxima ao centro de São Martinho, e lhe questionou sobre a possibilidade dele assumir a direção do

\footnotetext{
${ }^{11}$ Mauro Gruber era uma figura política importante em São Martinho até a época do trabalho de campo. Não participava mais ativamente da política, mas seu apoio era disputado pela maioria dos candidatos. No período de trabalho de campo, Mauro era paciente frequente da USF do Centro. Também era sócio da Sociedade Beneficente São Martinho, e seu nome podia ser visto no Clube, entre as demais propagandas pintadas em uma de suas paredes internas.
} 
hospital, para representá-lo quando preciso. Júlio aceitou. Passou a buscar fundos para pagar a dívida e, entre os grandes, da alta cúpula, nada conseguiu. Foi entre os colonos, que trabalhavam todo dia e juntavam pouco dinheiro, que Júlio conseguiu o empréstimo para pagar a dívida do hospital.

\section{O s grupose comunidade caminhos que se cruzam}

Júlio mantinha na Secretaria Municipal de Saúde uma equipe de mais de 40 pessoas, enquanto na Secretaria Municipal de Planejamento e Assistência Social sua equipe, contando com ele próprio, teria certamente menos de 5 pessoas. Não era gratidão, então, aquilo que guiava seu discurso: muito pelo contrário, era uma insatisfação manifesta em relação a seu grupo político, especialmente com o vice-prefeito reeleito, Leonardo. E Júlio, como bem sabia o prefeito Paulo, não poderia se desvencilhar do grupo. Ele já havia demonstrado a importância de seu apoio político em eleições anteriores, como também bem sabia o principal candidato da oposição, Gil Fuccio. A equação não era complicada: em 2004, Júlio era presidente municipal do PMDB (Partido do Movimento Democrático Brasileiro), mesmo partido de Gil, que, aliás, havia sido o primeiro prefeito de São Martinho após sua emancipação política. Júlio era tido como certo para sair-se candidato pelo partido, planos colocados em suspensão quando Gil inscreveu-se para as eleições internas e derrotou a candidatura de Júlio. Gil elegeu-se novamente prefeito de São Martinho e Júlio chegou a participar de seu governo, o que não durou muito, porque, segundo seu sobrinho Zeca - presidente do PTB (Partido Trabalhista Brasileiro) martinense - Gil subiu no palco e governou sem o grupo. Júlio então deixou o governo e o PMDB e fundou o PPS (Partido Popular Socialista), levando com ele mais de 70 pessoas, tanto do governo quanto do PMDB. No entanto, como uma figura polêmica, Júlio não sustentou o novo grupo formado em torno do PPS, que rachou com a saída de Zeca, o qual fundou o PTB em São Martinho. No momento da 
pesquisa de campo, Júlio presidia o PSB (Partido Socialista Brasileiro), que formava uma coligação política com o PSDB (Partido da Social Democracia Brasileira), PDT (Partido Democrático Trabalhista) e PP (Partido Progressista) - este último, presidido pelo prefeito Paulo Ritter. $\mathrm{O}$ apoio de Júlio e o esforço para manter seu descontentamento limitado, apesar das desavenças por ele criadas na gestão municipal, tinham então sua justificação histórica.

E como uma ironia política, no momento em que Júlio decidiu, em 2008, aliar-se a Paulo Ritter para derrotar sua então mais recente desavença, Gil Fuccio, mais uma vez sua candidatura foi minada pela coligação que ainda hoje governa São Martinho. Seu projeto era candidatar-se a vice-prefeito, o que não se concretizou quando Leonardo, então um desconhecido político, tornou-se a preferência para o cargo. Segundo o próprio prefeito, Júlio tinha certamente muito mais capacidade para o cargo, mas foi justamente sua postura contenciosa que o tirou da disputa. Por isso também que a posição de Júlio era delicada dentro do grupo de Paulo, pois, para Júlio, era certo que havia sido Leonardo o instigador de sua saída da Secretaria de Saúde. Ainda assim, Júlio manteve-se aliado a Paulo, não sem projetos futuros, o que certa vez "deixou escapar" - o que, certamente, não foi um descuido.

Os grupos de São Martinho não são, em si, uma composição política sem ressonâncias. Camargo (2012, 2015) já analisou sua atuação no sertão do Pajeú, Pernambuco. Trata-se de uma coletividade dinâmica, em que não há estrutura hierárquica definida, mas certamente há posições de liderança, o que pode ser altamente variável para algumas posições adjacentes - como aquelas conquistadas principalmente pelo cargo ocupado na administração pública -, mas o que pode ser constante para posições de maior destaque, como aquelas que agregam maior apoio político independentemente do cargo ocupado, como era o caso de Paulo, Júlio e Gil em São 
Martinho. Os grupos se assemelham, mas também se diferenciam da formulação clássica de Palmeira (1996) sobre as facções: ainda que suas bordas e suas fronteiras sejam visíveis especialmente na época da política, sua composição apresenta uma constância no tempo e, principalmente, as tramas de parentesco que formam e os partidos que agregam parecem manter-se entre os momentos de disputa política, salvo, é claro, quando se trata de rompimentos internos ao grupo. Em São Martinho, grupo, família e comunidade eram noções codependentes, que remetiam umas às outras.

O grupo era uma expressão da comunidade, sua tessitura política e do mesmo modo seu "espaço público", ou em melhores palavras, o meio que permitia uma série de vias de comunicação entre gestores, funcionários e moradores de São Martinho. Formava esse campo de comunicação (Marques, Commerford e Chaves, 2007, p. 47-48) que permitia o fazer político, assim como fazia circular as notícias e os avisos da política, sendo as primeiras uma série de conjecturas a respeito da disputa eleitoral e os avisos uma série de mensagens encaminhadas ao opositor político, sempre, em ambos os casos, sem remetente esclarecido, como um rumor sem ponto de partida. Por fim, o grupo permitia ainda a disputa por votos, que muitas vezes se dava pela troca por ranchos - cestas básicas -, a compra de votos, sabida e usual especialmente na véspera do pleito eleitoral. A unidade do voto, conquistado ou trocado, não era o "indivíduo", mas a casa, noção vinculada à de família, que certamente lembra - mas também são casos distintos - aquilo que Palmeira (1996, p. 51) chamou de voto múltiplo. A desvinculação da agência do voto em relação à casa era um processo complicado, e acompanhei apenas um caso em que uma funcionária da Saúde conseguiu provar que, mesmo sua família tendo votado em Gil Fuccio, ela havia votado em Paulo. E como um conjunto que não cessa de remeter-se a si mesmo, a garantia do voto era certamente a garantia de vias de comunicação privilegiadas, garantia de acesso a gestores e funcionários públicos. 
O grupo, desse modo, e tudo aquilo que o envolvia, como burocracias, disputas e alianças políticas, não se comportava à parte da organização social martinense, assim como da ética e da moral que lhe era vinculada. Muito pelo contrário, o grupo se manifestava enquanto os caminhos privilegiados pelos quais a política se realizava em suas relações sociais, tendo por conta sua correlação com as demais formações que sustentavam a noção de comunidade, como justamente a noção de casa, mas também as próprias tramas de parentesco para além desta noção. Um dos modos de diferenciar a família dos demais parentes em São Martinho é justamente o cuidado dispensado para manter uma casa, especialmente relacionada à outra noção fundamental para os alemães, a noção de trabalho, assim como se judiar em sua realização. Assim, aqueles que não possuem qualquer partilha em relação à casa, ao seu trabalho ou à sua dor, provavelmente será um parente que, no limite, une a todos os alemães. A não ser que pelo meio do caminho haja política. A política em São Martinho, como certa vez me lembrou Zeca a respeito das polêmicas de Júlio Hoff, havia se tornado briga de família. Isso porque Zeca, como apontado, era e ainda se considerava sobrinho de Júlio, filho de sua irmã, apesar da oposição política. 0 mesmo não se dava na relação entre Júlio e a mãe de Zeca, que não se falavam há muito, e sequer poderiam ser considerados da mesma família, como ressaltou Zeca. Ademais, como já ressaltado, quando uma família declarava seu voto a algum candidato, dificilmente haveria espaço para algum grau ainda mais elementar de agência, o que fazia com que, durante a disputa eleitoral, as famílias de São Martinho se polarizassem em torno dos dois principais grupos políticos, rompendo momentaneamente a ideia de uma comunidade de parentes.

\section{U ma comunidadede alemães. ética e moral da dedicação ao trabalho}

Se a atuação política, principalmente através dos grupos, não está para fora da trama social atuante em São Martinho que se 
movimenta como uma socialidade ${ }^{12}$ - isto é, sendo correlata com os demais agrupamentos como família e parentes, assim como organizando as narrativas sobre o passado, a comunidade e sobre si mesmo -, sua justificação e as expectativas que nela são depositadas não podem ser fundamentadas em outra coisa se não na ética e na moral que move tal socialidade. 0 que nela se forma - e por isto mesmo não são sociabilidades ${ }^{13}$, como cheguei a defender em minha dissertação de mestrado (Oliveira, 2013) - não são apenas grupos, mas pessoas, lugares, famílias, parentes e governo. E, através dela, uma série de preceitos morais circula por São Martinho, e atua no modo como cada pessoa se forma e é chamada a se comportar, assim como cada família e o próprio governo se formam e são chamados a se organizar. Esses preceitos morais não são constantes e suas formulações dependem inevitavelmente das situações em que são ativados, como um jogo moral, no qual se trata sempre de guardar para si - seja uma pessoa ou um grupo - aquilo que é moralmente aceito e reservar para o outro aquilo que deve ser desdenhado, o

${ }^{12}$ Strathern (2006, pp. 42-44, 151-156), impulsionada pela proposta de Wagner (1974) trata as formações das terras altas de Papua Nova-Guiné como socialidades, como um modo de transitar pelos processos de diferenciação próprios aos Hagen, entre os quais a vida social era antes um movimento entre um estado singular e um estado plural - o que, no limite, implica que uma pessoa singular pode comportar as mesmas socialidades que o seu correlativo plural, o grupo -, do que uma divisão entre um nível doméstico e a-social e um nível político e social.

${ }^{13}$ Inevitavelmente, a categoria socialidade lembra outra, a de sociabilidade, de Simmel (2006, p. 59-82). A posição marginal de Georg Simmel na academia alemã da virada do século XIX para o XX talvez tenha o possibilitado a se posicionar entre a disputa dos franceses Émile Durkheim e Gabriel Tarde, mas também, em parte, paralelamente às propostas de Max Weber em relação à "ação social”. Para Georg Simmel, a sociação representava justamente o movimento que fazia a sociedade derivar da interação individual, mas também a interação derivar dos círculos sociais dispostos pela sociedade. A sociabilidade seria uma forma particular de sociação, uma trama formada e disposta pela mútua determinação e interação daqueles que a compõem, no entanto, sem qualquer finalidade de princípio que implicasse a participação - o que vai em sentido oposto à ideia de "ação social". No entanto, a noção ainda implica justamente a dualidade que Roy Wagner e Marilyn Strathern buscam romper com a noção de socialidade, a de indivíduo/ sociedade. É por entender que tal dualidade também não opera em São Martinho, que se parte, neste artigo, dessa noção como norteadora das composições sociais observadas. 
que Herzfeld (1987, p. 140) chamou de shifter moral, enquanto uma operação estratégica de avaliação moral, que acionava o nós e o eles, aquilo que era atributo pessoal e aquilo que era a falta deste atributo; enfim, uma apreciação daquilo que era admirável e daquilo que era desdenhado ${ }^{14}$. Tudo isso dependia da situação em que um atributo pessoal era utilizado enquanto categoria de diferenciação. Nesse sentido, a distinção moral assumia um conteúdo disperso, tácito e estratégico (Villela, 2010, p. 176), expresso na fala, que definiam posições e constituíam continuamente uma sócio-lógica das relações (Herzfeld, 1987, p. 139; Seeger et al, 1979, pp. 12-13). Nesse jogo moral, várias questões eram problematizadas: a distribuição das atividades diárias; o uso de espaços reservados aos homens e às mulheres; a disposição e o vigor físico; a alimentação, sua produção e distribuição; a distribuição das atividades domésticas; a maturidade necessária para se gerir a vida adulta, entre outros tantos temas. No entanto, se fosse preciso inferir ao menos um ponto em comum a todos esses temas, este ponto - este problema para os alemães - seria a tríade formada pela disposição para o trabalho, a dor de sua realização e o sofrimento de sua narrativa. Os dois últimos termos são inferências do que os alemães chamavam de se judiar.

Era no trabalho que estava, sem dúvida, o apelo moral do discurso de Júlio àqueles que o ouviam. Pois o trabalho, diziam meus interlocutores de pesquisa, judia: certa vez Rubens, alemão e morador do segundo maior bairro de São Martinho, a Vila das Araucárias, o qual eu sempre fazia questão de visitar em meus períodos de trabalho de campo, disse-me a respeito dos primei-

\footnotetext{
${ }^{14}$ Operação comum nas etnografias da "antropologia do mediterrâneo" (Marques, 1999). Ver, por exemplo, a etnografia clássica de Pierre Bourdieu entre os Cabila (Bourdieu, 2006) e sua discussão sobre o "ponto de honra", assim como o trabalho de Anton Blok na Sicília (Blok, 1981) e sua discussão sobre a "força". Apesar das críticas mais recentes sobre a dualidade moral que movia tais análises - entre honra (universo público e masculino) e vergonha (espaço doméstico e feminino) -, como a excelente crítica de Unni Wikan (Wikan, 1984), estes trabalhos já apontavam para o universo moral como algo estratégico, disputável e operacionalizável.
} 
ros colonos: "Olha, essa gente se judiou quando chegou por aqui. Mas com eles era assim, ou trabalhava ou morria de fome". Outra vez ainda, Sônia, moradora do Centro me disse a respeito do trabalho nas indústrias calçadistas, nas fábricas: "Era um trabalho muito judiado. Mas era um bom trabalho, dava dinheiro". De modo que, a despeito do sofrimento implicado no ato de trabalhar, o trabalho assumia aquilo que Foucault (1988, p. 26-31) chamou de substância ética, isto é, era o modo privilegiado pelo qual os alemães eram chamados a se comportar enquanto sujeitos morais, através das regras de conduta e das práticas de si específicas, como modos de assegurar a subjetivação moral. Em cada caso, um aspecto singular da conduta constituiria o eixo fundamental da problematização moral: entre os alemães, tudo levava a crer que este eixo era formado pelo trabalho/dor/sofrimento.

Pois quando Júlio falou a respeito da formação da comunidade de São Martinho, quais eram os pontos tocados? Em primeiro lugar, uma certa quantidade de migrantes dirigidos ao meio do nada, que construíram a estrada que os ligava a Porto Alegre, construíram suas casas e, como nada lhes foi dado de bandeja, ajudavam a construir as casas de seus vizinhos. Do mesmo modo, pela falta de uma direção religiosa, construíram suas próprias igrejas, assim como seus próprios locais de ensino, nos quais aqueles de melhor índole moral guiariam toda uma comunidade que dependia apenas de seu trabalho para manter sua existência. Era o que me dizia Rubens: as casas, segundo ele, começavam sempre pelo paiol. Era primeiro o paiol que se fazia para garantir a continuidade da produção da roça; apenas depois se iniciava a construção da casa: e aqui, fazia-se tudo, das vigas do enxaimel às telhas do telhado, e tudo, garantia Rubens, em tal perfeição que, se chovesse, não caía uma gota dentro de casa. De modo que, em São Martinho, tudo se iniciou, segundo os relatos, de um mesmo ato: o trabalho das famílias pioneiras. Era esse o passado moral que se fazia circular por entre moradores e gestores, era essa a conduta esperada daqueles que se diziam alemães e era esse o apelo de Júlio aos seus ouvintes. 
Enquanto uma atividade que envolvia a própria constituição de si, o trabalho era alvo de cuidado e de apreço, e era pelas apreciações que se fazia sobre quem trabalhava ou deixava de trabalhar que esta atividade ganhava uma dimensão pública, pela qual era possível constituir e classificar homens e mulheres através de uma avaliação moral contínua. Isso implicava que mostrar-se adequado ao trabalho era tão importante quanto o ato de realizá-lo, e isto se dava de muitas maneiras: um homem alemão que não tivesse problemas em cumprir suas obrigações, não teria problemas em beber com os amigos, e era esperado que fosse, sempre tendo em mente o comedimento e a resistência que o uso da bebida implicava. Do mesmo modo, uma mulher não faria o uso diário da bebida como os homens, mas não pouparia esforços para manter sua casa e família assim como seu marido, realizando o trabalho doméstico e alguma atividade fora de casa, como a roça ou o trabalho nas indústrias calçadistas de São Martinho, as fábricas. Na negativa, quem não trabalhava estava encostado no INSS ou era simplesmente preguiçoso.

Tratava-se então de uma moral imanente à conduta que procurava lhe dar realidade e de uma ética que tinha por objetivo uma conduta que se julgava moralmente superior. A conduta, deste modo, não se desvencilhava da avaliação que procurava lhe situar. 0 trabalho, deste modo, assumia para os alemães dois níveis de realidade: o primeiro deles era um nível ético, de constituição; o segundo, um nível moral, de julgamento. Quanto ao primeiro nível, o trabalho era acompanhado da dor que lhe era imputado, o primeiro sentido do termo judiar-se; em seu segundo nível, o trabalho distinguia e hierarquizava pessoas e grupos de acordo com a operacionalização dos preceitos morais, acompanhado da valoração do sofrimento implicado na narrativa moral, o segundo sentido do termo judiar-se. 0 que se formava na efetuação cotidiana desse eixo ético-moral era justamente um modo de socialidade que formava e informava sobre corpos, pessoas - pessoas e corpos diferenciados pelo modo como eram chamados a 


\section{se comportar ${ }^{15}$ - casas, famílias, roças, parentes, comunidade e, claro, seu passado e suas narrativas.}

\section{E o modo como essa moral circulava era em sua expressão mais evidente, o hunsrik - ou tayxt, entre os moradores ${ }^{16}$-, uma varie- dade linguística trazida com os primeiros imigrantes, caracteri- zada ainda como a principal língua de São Martinho ${ }^{17}$. 0 hunsrik era um índice apreciativo evidente de um processo de subjeti-}

${ }^{15}$ Butler (1990, p. 128-141) propõe, a respeito do gênero, que são os próprios contornos corporais que são definidos pelas normas discursivas, na qual gênero não seria uma "identidade", mas um ato, uma performance no sentido de sua atualidade enquanto expressão corporal. Não se trata de uma escolha, mas de como certas normas traçam as fronteiras corporais e as interpelam a atuar de modos específicos, fronteiras que são reiteradas nestes mesmos atos - que Judith Butler chama justamente de "atos de gênero". Para o caso de São Martinho, há, claro, certas ressalvas. 0 trabalho, enquanto uma problematização moral, implicava que um alemão ou uma alemoa se formassem enquanto pessoas na própria constituição de seus corpos, os quais deviam ser resistentes, dispostos e comedidos em seus tratos. A diferenciação de gênero em relação ao trabalho era algo sempre muito complicado, pois tanto um alemão quanto uma alemoa eram chamados a estarem sempre dispostos à sua realização. Outros espaços e outras atividades eram mais eficazes na produção de gênero, como o ato de beber entre amigos, frequentar os clubes ou bodegas da cidade, ou ainda fechar negócios, reservados aos homens. Por fim, a produção de um corpo diferenciado não se tratava de sua técnica: era, antes, a definição mesma de suas fronteiras, de seus limites, de sua disposição espacial e, claro, de sua singularização, o que não era nada evidente.

${ }^{16}$ Desde 2004, um grupo de estudiosos, principalmente linguistas vinculados à UFRGS, mas também um grupo de historiadores de São Martinho, empenham-se em formalizar a escrita da língua falada na cidade, batizada, pelo grupo, de Hunsrik - principalmente para diferenciá-la do alemão contemporâneo, vinculando-a a um duplo local de origem: a Encosta da Serra e o Hunsrück, no sudoeste alemão, principal local de origem das famílias pioneiras. 0 projeto hunsrik conseguiu, em 2008 , formalizar uma gramática para a língua. A permanência do hunsrik em São Martinho adquiriu o status de um projeto cultural, tendo todo o seu arquivo na Casa da Cultura, onde se encontram, também, os registros censitários do município, objetos históricos, panfletos ilustrativos etc. Atualmente, até um micro-dicionário já existe para o hunsrik, "Mayn Ëyerste 100 Hunsrik Wërter" (Minhas primeiras 100 palavras em Hunsrik), que foi me dado logo em minha chegada à cidade.

${ }^{17}$ Dentro de uma casa ou no interior de uma família, a língua que se aprende é o hunsrik que, depois, cede espaço ao português, aprendido nas escolas e nos colégios. Entretanto, longe de o substituir, o português - ou brasileiro - se torna uma segunda língua, acessada em ocasiões específicas, como reuniões oficiais da administração pública, comércio, atendimentos públicos ou mesmo em conversas, quando não se sabe se aquele que lhe escuta é ou não um alemão. 
vação singular, que marcava um ritmo, um estado corporal, uma organização familiar e uma noção de comunidade que remetiam uns aos outros na definição de seus aspectos. A comunidade de São Martinho devia sua existência ao trabalho comum de alemães, que pela boa conduta em relação à atividade do trabalho eram capazes de se dedicarem à comunidade e às suas casas e famílias com total controle de seu tempo. 0 hunsrik era a língua que regia a categorização de todo esse processo, o modo de expressão singular pelo qual era possível problematizar as condutas e operar as avaliações que as hierarquizavam. O hunsrik fazia com que a própria fala de um alemão ou de uma alemoa os distinguisse em sua heterogeneidade.

Era em hunsrik que se operava a tradução classificatória de se dizer alemão, assim como a oposição que se atualizava e agia como propulsora do mesmo processo, que tinha como categoria preferencial os $x$ warts $^{18}$, categoria em hunsrik, que podia ser traduzida por dois termos sinônimos: negão e de fora, que geralmente eram dirigidas aos poucos moradores que se supunha não participarem daquela genealogia que os unia às famílias pioneiras. Em primeiro lugar, a oposição não expressava apenas uma dimensão geográfica: o que estava em jogo era, principalmente, uma posição exterior às condutas e agrupamentos que poderiam informar o que era ser alemão ou uma alemoa, que era partilhada por outras cidades da região, como Germana, onde também poderia ser encontrado o hunsrik. Em segundo lugar, a dimensão racial impressa na categoria era sempre relacional, apesar de sua tradução. A racialização (Bhabha, 2001, p. 111) operada para com aqueles de fora era sempre uma operação singular, um marcador de diferença que transformava a todos que se supunham não alemães em negão, e um de fora provavelmente seria chamado de negão, o que não levava em conta apenas a cor da pele ou qualquer outro traço fenotípico. No processo de

\footnotetext{
${ }^{18}$ A grafia foi retirada do Mayn Ëyerste 100 Hunsrik Wërter, o microdicionário de hunsrik, apresentado acima.
} 
distinção, era a própria força da categoria que preenchia de realidade os xwarts, assim como, na oposição, os alemães.

E assim como as genealogias traçavam em processo diacrônico quem poderia ser chamado de alemão ou alemoa, as roças e as casas repartiam este plano comum em tramas menores. A roça também fazia parte daquela conduta que se julgava própria aos alemães, que possibilitava que se tirasse dela grande parte do sustento de uma casa e de uma família. De modo algum, manter uma roça era uma alternativa ou impedimento de um possível trabalho concomitante em alguma fábrica, que, como apresentado acima, empregava grande parte da população martinense ${ }^{19}$. 0 que se via pelas ruas eram grandes roças que tomavam quarteirões inteiros e pequenas hortas de fundo de quintal, comuns em boa parte das casas. 0 que se produzia na roça era fruto do trabalho e sabia-se muito bem de onde vinha: ou da própria plantação ou de uma roça vizinha. Rubens era especialmente crítico aos produtos industrializados, mas a suspeita era comum entre os alemães: leite de caixinha era utensílio para casos de emergência, assim como hortaliças, legumes e galinhas eram buscados, antes, entre os vizinhos. Saber a procedência dos alimentos era, sem dúvida, a informação nutricional mais importante que se poderia ter. $\operatorname{~graxa}^{20}$, que os alemães utilizavam na preparação de todo alimento, assim como os legumes provindos da roça, julgava-se dar vigor e resistência ${ }^{21}$ à rotina de trabalho, e dona Joanna, mãe de Rubens e na época do trabalho de campo com 88 anos, era o exemplo regular para que o filho sustentasse sua opinião. Vigor que era compartilhado pelos alemães, e categorizado em oposição aos preguiçosos e aos xwarts.

\footnotetext{
${ }^{19}$ Ver nota 6.

${ }^{20}$ Gordura animal. Pode se referir tanto àquela gordura encontrada em assados e cozidos de boi, porco e galinha, como à gordura utilizada para o preparo de alimentos, como banha de porco e óleo de soja, muito consumidos em São Martinho.

${ }^{21}$ Em sua etnografia entre as "classes populares", Boltanski (2004, p. 63-76) observou essa relação através do uso da categoria forte. Dizia-se, por exemplo, de um alimento que se julgava revigorar o corpo, que era forte, assim como forte era aquele medicamento que se julgava extremamente eficaz, o qual o uso requereria cuidados especiais.
} 
O caso mais comum era que cada roça fosse partilhada por uma família, a não ser em casos excepcionais, como o caso dos irmãos Jung, grandes produtores de batata da Vila das Araucárias, que então possuíam alguns empregados - Jung, aliás, era um sobrenome partilhado com a família mais rica de São Martinho, donos de vários estabelecimentos comerciais. Desse modo, fazia-se uma tríade: o cuidado da roça era partilhado pelas mesmas pessoas que partilhavam o cuidado de uma casa, a família. E aqui muitas coisas entravam em jogo: pois, como notava Marques (2002, p. 120), para o sertão de Pernambuco, no limite, todos eram parentes. Era o que me dizia Rubens, que mantinha parente por toda a Encosta da Serra, era também o que me dizia Beatriz Bauer, genealogista e historiadora de São Martinho. Em sua catalogação dos primeiros loteamentos da Encosta da Serra estavam ali já os mesmos sobrenomes que ainda circulavam pelos moradores, como um grande plano endogâmico que remetia todos à mesma origem. Ou quase todos porque, é claro, para fora estavam os xwarts. Esse era um modo de se pensar parentesco em São Martinho, especialmente ativado quando se tratava a falar a um $x$ warts, como eu, o parentesco. Com um pouco mais de tempo em campo, no entanto, outros ingredientes fraturavam esta relação. A casa e o trabalho eram dois deles.

A categoria casa implica um certo conforto para a análise, pois encontra similitude no conceito formulado por Lévi-Strauss (1979, p. 143-167). Entretanto, não pode ser isenta de problematização. Para o autor, a casa, enquanto uma pessoa moral, atua na definição de quem é "natural" e quem é "de fora". Compõe em si forças de orientações contrárias, como filiação e residência, descendência matrilinear e patrilinear, exogamia e endogamia etc. (p. 160-164). Entretanto, as compõem em uma rede de direitos e obrigações, que tem na organização de parentesco seu meio de funcionamento, mas a dobra, e não oferece qualquer solução definitiva de organização social. Mas apesar do sinônimo ao conceito lévi-strussiano, a casa, em São Martinho, indica um movimento dinâmico de familiarização (Comerford, 2003, p. 
209-228), marcado principalmente pela solidariedade no trabalho em comum da família que busca mantê-la, além de definir os limites desta mesma família. Trata-se, então, daquilo que Marques (2002, p. 129-130) observou também entre as vinganças de famílias no sertão de Pernambuco, de um cognatismo, isto é, de alianças e solidariedades que influem na proximidade e nas distâncias entre famílias e parentes que, quando acionados, podem formar grupos ou heterogeneidades, conforme o caso. 0 parentesco é resultante e influente, mas não princípio ativo.

A casa, desse modo, operava tanto a genealogia como a proximidade. No caso de Rubens, a singularidade de sua descendência devia-se ao fato de seu ramo de parentesco Schubert/Keller estar vinculado à casa de seus avós de linha materna (Schubert), construída na Vila das Araucárias em 1896. Seu bisavô de linha materna era um pioneiro Gross, talvez o sobrenome mais comum em São Martinho. Por isso mesmo, Rubens não hesitava em dizer que mantinha parente por toda a Encosta da Serra. No entanto, nenhum deles descendiam daqueles que construíram a casa de 1896 e, quanto à proximidade atual, destes, ninguém, além dele e de sua mãe, participavam do cuidado de sua casa atual, e muito menos de sua roça. Esse exemplo se repetia por São Martinho, e o cuidado era geralmente codificado pelo signo do trabalho, o trabalho árduo, que judia, mas que mantém a casa, agrega a família, faz com que um alemão ou alemoa deixe de ser guri ou guria para se tornar adulto, e participar definitivamente da manutenção de sua comunidade. Assim, a despeito da ativação de uma origem comum, diferenciam-se as casas, os ramos menores, as famílias e, claro, as pessoas, aqueles de boa ou má índole moral. Tudo isso, entretanto, não era uma estrutura agnática ${ }^{22}$ de descendência, mas um jogo estratégico de composições.

\footnotetext{
${ }^{22}$ Aliás, como uma ironia relacionada ao problema que São Martinho coloca em relação à categoria Estado, não é novidade a característica "estatal" do sistema político proposto por Evans-Pritchard, especialmente em relação à segmentaridade da linhagem Nuer, que daria seu aspecto "social", em oposição às relações de certo modo "individuais" em operação do interior dos grupos domésticos, da ordem do parentesco. Sobre isso, ver Viveiros de Castro (2002, pp. 297-316).
} 


\section{Considerações finais: composições de governo e as análises do Estado e da política}

Um jogo estratégico, para retomar mais uma vez o pequeno discurso de abertura deste artigo, em que Júlio Hoff era implicado, mas que também sabia, mais do que qualquer outro, dobrá-lo a seu favor. 0 governo, mais do que qualquer outra trama, deveria ser o terreno por excelência desta moral do trabalho, de sua dor e sofrimento que circulava pela socialidade martinense. Cada grupo político buscava ligar a si a consequência dessa história moral, e Júlio, como uma figura incerta na disputa política, era a própria consequência desta história, era ele o homem de "boa índole moral" da disputa política de 2012. Isso implicava que, durante a disputa eleitoral, todas aquelas formações de pessoa, casa ou família eram chamadas a compor grupos, e, na vitória, a compor governo. Não à toa, a unidade mínima da disputa, como apresentado acima, era a família, e não a pessoa, em uma distribuição da agência em que o voto lhe negava a existência. No entanto, no período de governo, as trocas poderiam ser estritamente pessoais, não lhe isentando o fato dessa pessoa ter que compor família entre aquelas que declararam voto ao grupo vencedor. Assim, as vias de comunicação estabelecidas na disputa política e mantidas durante o período de governo reorganizavam mais uma vez esta existência ideal que era a comunidade, repartia mais uma vez esta formação em ao menos dois conjuntos, aqueles que faziam ou não parte do governo. Havia as posições vacilantes, como a de Júlio, sempre suspeito de se retirar do grupo vencedor, que não por menos ligava a si, e não ao governo, a história moral das famílias pioneiras.

Havia ainda outro motivo para que o prefeito preferisse ter Júlio por perto, além de sua importância política incontestável: poucos dominavam a burocracia institucional como Júlio. E isso nos leva ao último ponto deste artigo: nesta formação que era o governo, não havia apenas grupos e famílias, ética e moral, e mesmo partidos ou coligações, havia também a imensa burocra- 
cia que implica uma administração pública, e isto não escapava ao cálculo de seus gestores. No entanto, essa burocracia não silenciava as estratégias políticas e muito menos as estratégias tinham o poder de subjulgar a legalidade burocrática. Tratava-se mais uma vez de composição. Pois, para falar de política local, a opção clássica do pensamento social brasileiro foi pensar em um sistema de reciprocidade entre o Estado e o local, entre a máquina burocrática e o coronel. 0 local por excelência da análise era o "sertão nordestino" como o lugar da ausência, ou o não-lugar do Estado, analisado enquanto lócus da política local dos "coronéis", o "tropo" do poder público (Leal, 1997 [1948]). No entanto, as análises como as de Vitor Nunes Leal, Sérgio Buarque de Holanda (Holanda, 1976 [1936]) e Raimundo Faoro (Faoro, 2000 [1958]) tinham o seu quê de temporalidade - o que, de outro modo, não explica como estas opções se arrastaram para até os anos 2000, na nova roupagem analítica do "clientelismo" (Kerbauy, 2000).

As trocas pessoais, as famílias, o local, assim como as intermediações que se lhes creditava, eram desta forma vistos e analisados como um entrave a uma possível composição estatal no Brasil, um resquício com lugar estabelecido, as zonas rurais e periféricas, especialmente categorizadas enquanto o sertão nordestino. Não à toa, durante a década de 1970, dois amplos projetos de pesquisa ofereceram o material para que se questionasse essa abordagem: um deles, coordenado por Roberto Cardoso de Oliveira e Maybury Lewis, Estudo Comparativo de Desenvolvimento Regional; o outro, coordenado por Moacir Palmeira, Emprego e Mudança Sócio-Econômica no Nordeste (Godoy, 1999, p. 23). Ambos foram desenvolvidos especialmente em Pernambuco, e os trabalhos que deles resultaram questionavam justamente o avanço da economia capitalista frente aos modos de vida camponesa, sua organização e sua composição frente às novas condições de trabalho, especialmente na expansão latifundiária da zona da mata. A questão então muda de valor ao se questionar sobre a organização social e econômica camponesa, em vez de 
problematizar os obstáculos à organização de um tipo ideal de espaço público. Do projeto de Moacir Palmeira resultou outro, a criação de um núcleo de antropologia da política, que passou a reunir trabalhos que versavam sobre a composição política em diferentes lugares etnográficos, alinhados na premissa de que a lógica política e seus arranjos de governo sempre formavam uma disposição singular, operante e transitiva, a despeito de uma divisão entre uma política local e um suposto sistema político nacional.

Os trabalhos da antropologia da política transitaram por objetos de pesquisa diversos, desde disputas políticas no sertão de Pernambuco (Camargo, 2012; 2014; Villela, 2010), até a composição de alianças e bases de parlamentares no Congresso Nacional (Bezerra, 2003) ou a disputa pelo governo do Distrito Federal (Borges, 2003). A primeira coletânea de expressão acadêmica foi organizada por Palmeira e Goldman (1996). O trabalho de Palmeira (1996), em especial, ainda se caracteriza como o principal interlocutor, principalmente pela noção por ele desenvolvida de “época da política”. Para o autor, a época da política se organizava enquanto um recorte do tempo social em que desavenças e brigas, assim como facções, eram atualizadas na disputa eleitoral, evidenciando fronteiras que se tornavam menos visíveis fora da disputa. No entanto, em trabalhos mais recentes, como o próprio trabalho de Camargo (2012; 2014), além do trabalho de Marques (2002) e Comerford (2001), as disputas políticas e aquelas que podem assumir outros níveis legais de resolução não constituem apenas grupos ou facções, mas passam a traçar parentesco e definir famílias, compondo e localizando sujeitos na própria geografia relacional das disputas e alianças.

Uma proposta levemente distinta daquela encontrada no conjunto de autores que se voltam para as margens do Estado (Das e Poole, 2008; Nadai, 2014, 2012; Ferreira, 2013; 2014; Rui, 2012; Feltran, 2010, 2011; Machado da Silva, 2008), que apostam na incapacidade de referenciar-se ao Estado isentando-se de suas 
disputas cotidianas, mas que partem de contextos de pesquisa nos quais, ao menos enquanto categoria de poder, o estado se apresenta de modo inconstante. De todas essas contribuições, a de Das e Poole (2008, p. 19-52) é, sem dúvida, a mais debatida pelos demais autores citados. As margens seriam justamente aqueles espaços nos quais a governamentalidade, a regulação e a disciplina se expressam cotidianamente: a visibilidade do Estado se realizaria na disputa, na querela diária por sua primazia em governar, regular e disciplinar. Isto é: seria justamente naqueles espaços nos quais o Estado não adquiriu a hegemonia pretendida que podemos ver o Estado, um Estado em ação, um Estado que reivindica seu direito de Estado, muitas vezes a partir da mediação de modos de regulação que poderiam ser considerados concorrentes - como comunidades de base, igrejas católicas, igrejas pentecostais ou neopentecostais, polícia, serviço social, mundo do crime, ONGs etc.

Noções pouco ou nunca operacionalizadas por aqueles envolvidos na burocracia política e administrativa, como espaço público e Estado, passaram a perder o valor de conceito e a retornar ao valor de categoria social, válida única e exclusivamente quando inserida em um universo categorial que fizesse sentido para seus participantes. 0 problema é que a análise social se deixou deslumbrar pelo conceito, e as composições de governo foram durante muito tempo chamadas indistintamente de Estado, duplicando uma divisão digna da filosofia política, entre sociedade política e sociedade civil, como se os modos de organização social não participassem eles mesmos do cotidiano das composições políticas, burocráticas e de governo. No entanto, quando se caminha em direção à Encosta da Serra, por lá encontramos uma administração pública altamente burocratizada, mas que de forma alguma é classificada enquanto Estado. Falar de composição de governo é apostar justamente na invalidade da oposição entre o Estado e o local como ordens essencialmente distintas, aposta que evidentemente só me foi garantida pela minha estadia em São Martinho. 
Muito daquilo que acompanhei em meus períodos de trabalho de campo foram discussões e reuniões de gestores, funcionários e conselhos deliberativos (assembleias, conselhos municipais, reuniões do Processo de Participação Popular e Cidadã ${ }^{23}$ ) na busca de saber como opções políticas poderiam se inserir na legalidade constitucional, ou, dito de outro modo, quais eram os espaços da legalidade constitucional nos quais se poderiam traçar as estratégias políticas. Isso não implica, no entanto, que o Estado fosse uma categoria válida para meus interlocutores de campo: as instâncias e formações eram sempre muito mais situadas do que este ideal. Era a prefeitura para os moradores que acusavam a gestão municipal; a saúde para os usuários do sistema público de saúde e mesmo para os gestores; o promotor de Germana para os gestores de São Martinho quando buscavam se referir ao promotor da Justiça Eleitoral de Germana; o secretário estadual para os administradores da saúde pública de São Martinho quando se referiam à Secretaria Estadual de Saúde e assim por diante. Nesse sentido, o Estado sequer era uma virtualidade: não possuía sentido categorial e muito menos uma unidade ideal; não era uma categoria operacionalizável.

Pois o Estado, como um conceito político e filosófico, não se realiza mecanicamente nas disposições políticas, burocráticas e governamentais atuantes no cotidiano. Com o passar do tempo, ele acabou se revestindo de poder explicativo para essas disposições que eram inevitavelmente singulares de acordo com o lugar e com o tempo que ajudavam a produzir. Dito de outra forma, o Estado

${ }^{23}$ O Processo de Participação Popular e Cidadã (PPC) integra o planejamento e elaboração do orçamento anual para o estado do Rio Grande do Sul. Seguindo o modelo dos Orçamentos Participativos (OPs), estrutura-se em cinco etapas, que integram Comudes (Conselhos Municipais de Desenvolvimento), Coredes (Conselhos Regionais de Desenvolvimento), as Coordenações Municipais e Regionais de Participação Popular e Cidadã, os Fóruns Regionais e, por fim, o Fórum Estadual, que vota e aloca as prioridades votadas nas demais fases do processo. No nível municipal, o Comude é responsável por chamar o PPC, assim como por apresentar as demandas e as áreas prioritárias de investimento, votadas anteriormente pelos membros do Corede (Secretaria de Planejamento, Gestão e Participação Cidadã, Rio Grande do Sul, 2014). 
passou de categoria de reivindicação política em um momento e lugar situado para um conceito de embasamento analítico, mais ou menos como se sucedeu com outras categorias hoje postas em suspenso, como "sociedade", "ciência" ou "cultura". Esse descolamento não é, de modo algum, um constructo atemporal. Implica o cercamento de uma esfera da vida política em relação aos demais modos de regulação social, como a família, o parentesco, os interesses, a amizade etc. A aposta de Foucault (2008a, p. 155-331) é de que o Estado, enquanto uma realidade apartada das demais formas de governo seria, no momento de seu nascimento, o que ele chamou de um "regime de veridição" (Foucault, 2008b, p. 49), isto é, um conjunto de regras que permitem estabelecer, a propósito de um discurso, quais enunciados podem ser caracterizados como verdadeiros ou falsos. 0 Estado, nesse sentido, seria uma "ideia reguladora" (2008a, p. 384-285), uma noção operacionalizada por uma série de teóricos envolvidos na reforma dos espaços de gestão entre os séculos XVI e XVII, que, na elaboração de uma "razão de Estado", buscaram definir o que era o Estado, quais eram seus limites, e o que certamente lhe caberia para a sua própria conservação. Nesse momento, o Estado adquire a posição e uma entidade em si mesma, algo a ser conservado no mesmo momento em que era produzido.

Em São Martinho, a categoria comunidade, como é utilizada pelos alemães, como o limite ideal da socialidade que envolve as pessoas, os corpos, os grupos, as famílias, as casas, as roças e o governo, se apresenta como uma opção privilegiada para se estudar o governo, a política e a burocracia municipal, isto porque as integra em seu jogo moral, as situa na ética dos alemães, na valoração daqueles que se judiam pelo trabalho. E no retorno da comunidade para minhas próprias opções de análise, por que haveria de falar de Estado? Pois quando retorno para a escrita observo a própria índole moral da análise social, esta moral que observa espaço público em oposição ao clientelismo, que observa filiação partidária em oposição aos grupos e à troca de votos, que observa o Estado em oposição às re- 
gulações morais. Em São Martinho, os elementos vistos como não-estatais, como essa moral estratégica que circula pela dor e sofrimento que agrega e desagrega grupos e pessoas na valoração do trabalho, podem estar no centro de funcionamento de seu governo. Na comunidade de alemães o governo não opera oposições, mas correlações ${ }^{24}$.

\section{Bibliografia}

BHABHA, Homi. 0 local da Cultura. Belo Horizonte: Editora UFMG, 2007.

BLOK, Anton. Rams and Billy-Goats: a key to the mediterranean code of Honour. Man. Londres, v. 16, n. 3, p. 427-440, set. 1981.

BOLTANSKI, Luc. As Classes Sociais e o Corpo. São Paulo: Paz e Terra, 2004.

BORGES, Antonádia. Tempo de Brasília: etnografando lugares-eventos da política. Rio de Janeiro: Relume Dumará, 2003.

BOURDIEU, Pierre. Tres Estudios de Etnología Cabilia. In: BOURDIEU, P. Sociología de Argelia e Tres Estudios de Etnología Cabilia. Madri: Centro de Investigaciones Sociológicas/ Boletín Oficial del Estado, 2006.

BRASIL. Constituição da República Federativa do Brasil. Rio de Janeiro: DP \& A Editora, 2005.

BUTLER, Judith. Gender Trouble: feminism and the subversion of identity. Nova Iorque/Londres: Routledge, 1990.

CAMARGO, Carla Souza. Entre partidos políticos, facções, redes e famílias: o que são os grupos políticos no sertão de Pernambuco?. Cadernos de Campo, São Paulo, v. 23, n. 23, p. 11-27, 2014.

Partidos e Grupos Políticos num município do Sertão de Pernambuco. Dissertação (Mestrado em Antropologia Social). Programa de Pós-Graduação em Antropologia Social, Centro de Educação e Ciências Humanas, Universidade Federal de São Carlos, São Carlos, 2012.

COMERFORD, John Cunha. Como Uma Família: sociabilidade, territórios de parentesco e sindicalismo rural. Rio de Janeiro: Relume Dumará, 2003.

${ }^{24}$ Foucault diria "o Estado nada mais é que uma peripécia do governo" (2008a, p. 331), mas podemos nos apropriar e dizer: o Estado nada mais é que uma peripécia da análise. 
DAS, Veena \& POOLE, Deborah. El Estado y Sus Márgenes: etnografías comparadas. Cuadernos de Antropología Social, Buenos Aires, n. 27, p. 19-52, 2008.

FAORO, Raimundo. Os Donos do Poder: formação do pratonato político brasileiro. São Paulo: Globo/Publifolha, 2000.

FELTRAN, Gabriel de Santis. Fronteiras de Tensão: política e violência nas periferias de São Paulo. São Paulo: Editora da UNESP/ Centro de Estudos da Metrópole-CEBRAP, 2011

. Margens da Política, Fronteiras da Violência: uma ação coletiva das periferias de São Paulo. Lua Nova, São Paulo, n. 79, p. 201-233, 2010.

FERREIRA, Letícia Carvalho de Mesquita. Disputas de papel: rotinas formais e demandas morais na administração de casos de crianças desaparecidas em um órgão de assistência social. In: 29a Reunião Brasileira de Antropologia, Natal, 2014. Anais da 29a RBA. Natal: Associação Brasileira de Antropologia.

"Apenas preencher papel": reflexões sobre registros policiais de desaparecimento de pessoa e outros documentos. Mana, Rio de Janeiro, vol.19, n. 1, 2013. Disponível em: <http://www.scielo.br/scielo.php?pid=S0104-93132013000100002\&script=sci_arttext>. Acessado em: 10/10/2015.

FOUCAULT, Michel. Segurança, Território, População. São Paulo: Martins Fontes, 2008a.

. Nascimento da Biopolítica. São Paulo: Martins Fontes, 2008b.

História da Sexualidade II: o uso dos prazeres. Rio de Janeiro: Edições Graal, 1988.

GODOY, Emília Pietrafesa de. 0 Trabalho da Memória: cotidiano e história no sertão do Piauí. Campinas: Editora da Unicamp, 1999.

HERZFELD, Michael. Anthropology Through the Looking Glass: critical ethnography in the margins of Europe. Cambridge: Cambridge University Press, 1987.

HOLANDA, Sérgio Buarque. Raízes do Brasil. Rio de Janeiro: Livraria José Olympio Editora, 1976.

INSTITUTO BRASILEIRO DE GEOGRAFIA E ESTATÍSTICA (IBGE). Base de Dados do Censo 2010. Disponível em: <http://www.ibge.gov.br/censo2010/ primeiros_dados_divulgados/index.php?uf=43>. Acessado em: 02/02/2011.

KERBAUY, Maria Teresa. $A$ Morte dos Coronéis: política interiorana e poder local. Araraquara: FCL Laboratório Editorial/Cultura Acadêmica editora, 2000. 
LEAL, Victor Nunes. Coronelismo, Enxada e Voto. Rio de Janeiro: Nova Fronteira, 1997.

LÉVI-STRAUSS, Claude. A Via das Máscaras. Lisboa: Editorial Presença, 1979. MACHADO DA SILVA, Luiz Antonio. Violência Urbana, Sociabilidade Violenta e Agenda Pública. In: MACHADO DA SILVA, L. A. Vida sob Cerco: violência e rotina nas favelas do Rio de Janeiro. Rio de Janeiro: Nova Fronteira, 2008, p. 35-45.

MARQUES, Ana Claudia Intrigas e Questões. Vingança de família e tramas sociais no sertão de Pernambuco. Rio de Janeiro: Relume Dumará, 2002.

Algumas Faces de Outros Eus: honra e patronagem na antropologia do mediterrâneo. Mana, Rio de Janeiro, v. 5, n. 1, 1999, p. 131-147.

MARQUES, Ana Claudia; COMERFORD, John Cunha \& CHAVES, Carla. Traições, Intrigas, Fofocas e Vinganças: notas para uma abordagem etnográfica do conflito. In: MARQUES, A. C. Conflitos, Política e Relações Pessoais. Campinas: Pontes Editores, 2007.

MINISTÉRIO DO TRABALHO E DO EMPREGO (MTE). Cadastro Geral de Empregados e Desempregados (Caged), Perfil do Município, 2012. Disponível em: <http://bi.mte.gov.br/bgcaged/caged_perfil_municipio/index.php>. Acessado em: 20/11/2012.

NADAI, Larissa. Os cartórios confessionais e seus silêncios: ouvir/narrar estupros numa Delegacia de Defesa da Mulher (DDM) de Campinas. In: 29a Reunião Brasileira de Antropologia, Natal, 2014. Anais da 29a RBA. Natal: Associação Brasileira de Antropologia.

Descrever Crimes, Decifrar Convenções Narrativas: uma etnografia entre documentos oficiais da Delegacia de Defesa da Mulher de Campinas em casos de estupro e atentado violento ao pudor. Dissertação (Mestrado em Antropologia Social). Instituto de Filosofia e Ciências Humanas, Universidade Estadual de Campinas, Campinas, 2012.

OLIVEIRA, Everton de. Promover a Saúde, Produzir Famílias: a implementação da Estratégia Saúde da Família na Encosta da Serra gaúcha. Dissertação (Mestrado em Sociologia). Programa de Pós-Graduação em Sociologia, Centro de Educação e Ciências Humanas, Universidade Federal de São Carlos, São Carlos, 2013.

PALMEIRA, Moacir. Política, Facções e Voto. In: PALMEIRA, M. \& GOLDMAN, M. Antropologia, Voto e Representação Política. Rio de Janeiro: Contra Capa, 1996.

PROGRAMA DAS NAÇÕES UNIDAS PARA O DESENVOLVIMENTO (PNUD), ORAGANIZAÇÃO DAS NAÇÕES UNIDAS (ONU). Atlas do Desenvolvimento Huma- 
no no Brasil. 2013. Disponível em: http://www.atlasbrasil.org.br/2013/pt/ consulta/. Acessado em: 23/01/2015.

RODRIGUES, Ricardo Donato. Programa de Residência em Medicina de Família e Comunidade da Uerj: uma perspectiva histórica. Revista Brasileira de Medicina de Família e Comunidade, Rio de Janeiro, v. 3, n. 11, p. 149-156, out.-dez. 2007.

RUI, Taniele. "Isso não é um Cachimbo": sobre usuários de crack, seus artefatos e suas relações. Áskesis, São Carlos, v. 1, n. 1, p. 32-45, jan.-jul. 2012.

SECRETARIA DE PLANEJAMENTO, GESTÃO E PARTICIPAÇÃO CIDADÃ-RS. Documentos e Orientações sobre o Processo de Participação Popular e Cidadã. 2013. Disponível em: <http://www.portaldaparticipacao.rs.gov.br/documentos-sistema/>. Acessado em: 14/05/2013.

SEEGER, Anthony. et al. A Construção da Pessoa nas Sociedades Indígenas Brasileiras. Boletim do Museu Nacional, Rio de Janeiro, n. 32, mai. 1979, p. 2-19.

SIMMEL, Georg. A Sociabilidade: exemplo de sociologia pura ou formal. In: SIMMEL, G. Questões Fundamentais da Sociologia. Rio de Janeiro: Jorge Zahar Editor, 2006, p. 59-82.

STRATHERN, Marilyn. 0 Gênero da Dádiva: problemas com as mulheres e problemas com a sociedade na Melanésia. Campinas: Editora Unicamp, 2006.

TRIBUNAL SUPERIOR ELEITORAL (TSE). Código Eleitoral Anotado e Legislação Complementar. Brasília: Tribunal Superior Eleitoral; Secretaria de Gestão da Informação, 2012. Disponível em: <http://www.tse.jus.br/hotSites/ CatalogoPublicacoes/pdf/codigo_eleitoral_2012/TSE-Codigo-Eleitoral-2012-Web.pdf>. Acessado em: 12/09/2012.

VILLELA. Jorge Mattar. Moral da Política e Antropologia das Relações de Poder no Sertão de Pernambuco. Lua Nova, São Paulo, n. 79, p. 163-199, 2010.

VIVEIROS DE CASTRO, Eduardo. A Inconstância da Alma Selvagem. São Paulo: Cosac Naify, 2002.

WAGNER, Roy. Are There Social Groups in the New Guinea Highlands? In: LEAF, M. Frontiers of Anthropology. Nova Iorque: D. Van Nostrand Company, 1974.

WIKAN, Unni. Shame and Honour: a contestable pair. Man, Londres, v. 19, n. 4, p. 635-652, dez. 1984.

WOORTMANN, Ellen. Herdeiros, Parentes e Compadres: colonos do Sul e sitiantes do Nordeste. São Paulo/ Brasília: Hucitec/ Editora da UnB, 1995.

Recebido em 15/12/2015

Aprovado em 30/12/2015 
